\title{
Speech-Language Pathologists' Perceptions of the Importance and Ability to Use Assistive Technology in the Kingdom of Saudi Arabia
}

\author{
Ahmad Mousa Al-Dawaideh ${ }^{1, *}$ \\ ${ }^{1}$ Department of Special Education, King Abdulaziz University, Saudi Arabia \\ *Corresponding author: Department of Special Education, King Abdulaziz University, Saudi Arabia \\ E-mail: drahmad1971@yahoo.com
}

Received: October 29, 2013

Accepted: November 26, 2013

Online Published: December 11, 2013

doi:10.5430/wje.v3n6p64

URL: http://dx.doi.org/10.5430/wje.v3n6p64

\begin{abstract}
Speech-language pathologists (SLPs) frequently work with people with severe communication disorders who require assistive technology (AT) for communication. The purpose of this study was to investigate the SLPs perceptions of the importance of and ability level required for using AT, and the relationship of AT with gender, level of education, training, place of work, and years of experience. To achieve this goal, the researcher adopted a questionnaire prepared by Currie et al. (1996) to determine SLPs perceptions of AT. The study revealed a number of results regarding SLPs perceptions of the importance and ability to use AT. The results indicated that all of the SLPs who participated in this study considered all of the items in the questionnaire to be valuable, and the respondents rated themselves as having a "low" to "high" ability of using AT. In addition, no statistically significant differences in the perceived importance and ability to use AT occurred between the male and female groups in all the categories and the total score of the scale. The results also indicated a statistically significant difference in the perceived importance and ability to use AT among the teaching experience groups and the training groups in all the categories and the total score of the scale. Participants with more years of experience and training produced more favorable results than the other participants did. In addition, no statistically significant differences in the perceived importance and ability to use AT occurred among the level of education groups in all the categories and the total score of the scale. Finally, a statistically significant difference in the perceived importance and ability to use AT occurred among the place of work groups in all the categories and the total score of the scale. The participants who worked in private settings produced more favorable results, except for the category "general computer knowledge", in which no statistically significant differences occurred among the participants.
\end{abstract}

Keywords: assistive technology (AT); speech-language pathologists (SLPs); importance and use

\section{Introduction}

Speech and language disorders limit the ability of students to communicate and interact with others. Speech and language disorders may be or not associated with disabilities, such as mental retardation, autism, cerebral palsy, and hearing impairment. Speech and language disorders can be mild or severe, and the severe cases require intensive and specialized services provided by SLPs.

SLPs use computers and other assistive technology (AT) to diagnosis and treat communication disorders (Al-Khateeb, 2005). In 1998, the Individuals with Disabilities Education Act (IDEA) required schools to use technology to teach children with various types of disabilities, and AT was subsequently used for developing the functional skills and abilities of these children (Reed \& Laham, 2005). In 1997, IDEA [P. 1. 105-17] required that AT be used in preparing individualized education programs (IEPs) [29 U.SC 2201, §3 (1)].

IDEA (2004) defines AT as “....any items, piece of equipment or product systems, whether acquired commercially off the shelf, modified, or customized, that is used to increase, maintain, or improve the functionally capabilities of students (or individuals) with disabilities.” AT has the powerful potential to benefit students with disabilities by contributing to their learning, independence, self-esteem, and quality of life (Reed, 2007).

AT has become an integral part of the development of children with disabilities and is gaining increased acceptance 
in the delivery of services in schools and rehabilitation centers. AT is efficient and can be used to motivate students, make tasks easier to perform, facilitate positive outcomes, and increase the opportunities for students to socialize and subsequently reduce isolation. In addition, AT supports a variety of learning styles and provides independent and immediate feedback (Green, 2011).

Technology facilitates the acquisition of communication skills and the rehabilitation of people with impairments in the gestural, verbal, and written modes of communication (Currie, Carr, \&Torrey, 1996, p. 19). A large amount of people in the world have communication disabilities that prevent them from relying on natural speech to communicate effectively on a daily basis. Alternative and augmentative communication (AAC) strategies have great potential to enhance the communication skills of people with complex communication needs (Beukelman \& Mirenda, 2005). AAC tools and systems are crucial components of AT. The American Speech-Language-Hearing Association (ASHA) defines AAC as “.... an area of research, clinical, and educational practice. AAC involves attempts to study and when necessary compensate for temporary or permanent impairments, activity limitations, and participation restrictions of persons with severe disorders of speech-language production and/or comprehension, including spoken and written modes of communication.” (ASHA, 2005).

Knowledge and skills associated with technology are essential for SLPs who provide services to people with communication disorders. In this context, numerous researchers have suggested that a lack of specialist knowledge on AAC will lead to a lack of AAC services that can be provided to people with complex communication needs (ASHA, 1981; Merill, Yilon-Hamivitiz, Weiss, Label, \& Seligman-Wine, 2000). Wynne and Hurst (1995) reported that when using computer technologies, SLPs should focus on clinical competencies and professional responsibilities to avoid ethical pitfalls and legal traps associated with the integration of these technologies in schools.

Numerous types of devices and AT tools have been used to treat communication disorders, including communication voice output, communication software, telephones, and videophones (Green, 2011). SLPs can use this type of technology for assessing, diagnosing, and treating communication disorders (Currie et al., 1996).

\section{Literature Review}

SLPs often use AT to facilitate the teaching of communication to people with disabilities. Several studies have been conducted to investigate SLPs perceptions of AT.

In a survey conducted by Currie et al. (1996) in which 45 SLPs participated, 29 out of 30 items in the questionnaire produced a mean rating of 3.0 or higher ( 4-point scale), indicating that each competency statement was considered by respondents to be "moderately important" to "very important." In addition, they reported that no statement received a mean rating of 2.83 or greater, indicating that the respondents were only "some what" to "modeately" confident in their ability to execute each competency. The majority of the respondents described themselves as beginners in using both computers and AT, and $44.5 \%$ of the respondents reported that they had received more training in using computers than in using AT (26.6\%).

Marvin, Montano, \& Gould (2003) assessed SLPs perceptions of their training and experience in using alternative and augmentative communication systems. Participants were asked to share their perspectives on the use of AAC systems, focusing on four key elements: self-perceived qualifications, education and training, frequency of use, and frequency of recommendations. The results of the study conducted by Marvin et al. indicate that more than half of the participants received limited or inadequate training in using AAC, and $80 \%$ of the participants reported that the graduate courses they had taken provided them with insufficient knowledge on speech and language pathology. In addition, the majority of the participants indicated that they were not comfortable using AAC systems. However, the results of the survey conducted by Balandin and Iacono (1998) revealed that 98\% of the participating SLPs had some knowledge of AAC and 13\% did not recommend using AAC in a professional setting. These SLPs did not recommend using AAC because they had limited knowledge and skills related to this type of communication. In addition, based on the results of a survey, Wehmeyer (1998) reported that the primary barrier to using AT for parents of people with mental retardation is the cost of AT devices.

Chmiliar (2007) reported that the results of his survey revealed that 97\% of the participating SLPs reported that they had received training in using AT, and $44 \%$ of the SLPs reported that they were somewhat proficient in using AT. In addition, the SLPs reported a high level of competence in using AT. Chmiliar also reported that $59 \%$ of the SLPs were dissatisfied with their current skills and knowledge of AT, and only $28 \%$ were satisfied or very satisfied. The SLPs stated funding was the most crucial factor in implementing AT. As relevant study, Eugene (2006) investigated how teachers' attitude and beliefs may make an impact on integration of technology in their classes. The study 
sample consisted of thirty-two teachers who responded to the questionnaire to measure the attitude and beliefs about integration of technology in teaching. The results revealed that there was a contradiction between teachers' beliefs and the actual instructional practices of integrating technology.

Compton, Tucker, and Flynn (2009) examined the levels of preparedness of North Carolina SLPs who assisted school-aged children with cochlear implants (CI). The sample consisted of 190 specialists. The results indicated that $79 \%$ of the participants had no confidence in using CI technology. The results also indicated that the SLPs were not instructed on hearing topics in related undergraduate and graduate courses.

Ismail, Almekhlafi, and Al-Mekhlafy (2010) investigated the perceptions of both teachers of Arabic and teachers of English about the use of technology in their classes in United Arab Emirates' schools. 621 teachers responded to the questionnaire to collect the data. The results emphasized teachers' perceptions about importance role of technology in first and second language teaching and learning. Furthermore, the teachers showed the willingness to accelerate the integration of technology in their classes to improve language teaching and learning.

Khaleel and Al-Dawaideh (2012) conducted a survey to evaluate the level of importance and possession of SLPs competencies, according to the standards of the Council for Exceptional Children and from the viewpoint of SLPs in the Kingdom of Saudi Arabia. The sample of this study comprised 40 SLPs (21 male and 19 female) who worked in various environments (general education schools, special education centers, rehabilitation centers, speech clinics, and hospitals) in the Kingdom of Saudi Arabia. To achieve the goals of the study, the researchers developed a questionnaire to identify SLPs competencies. The final version of the questionnaire consisted of 40 items. The results indicated that the SLPs considered all of the items addressing "SLPs competencies" as "important." The mean for the degree of importance was 4.6 and the mean for possession was 3.37. The results indicated no significant differences in the level of importance and possession can be attributed to gender, academic level, years of experience, or the workplace.

\subsection{Statement of the Problem}

The SLPs have broader roles and responsibilities relative to AT. Therefore, the findings have important implications as SLPs become more responsible for the application of AT in service delivery for individuals with communication disorders. The current study was conducted in response to the limited available research concerning the professional preparation of SLPs related to the use of AT in Kingdom of Saudi Arabia.

\subsection{Purpose of the Study}

The main purpose of this study was to assess SLPs perceptions of the importance and ability level of using AT in the Kingdom of Saudi Arabia. The differences in importance and ability levels related to gender, level of education, training, place of work and years of experience were also identified. Therefore, the following questions were addressed:

1) Which competencies of AT were perceived by SLPs as the most important?

2) Do mean differences in the perceived importance levels of AT exist between SLPs demographic categories (gender, level of education, training, place of work, and years of experience)?

3) Which competencies of AT were perceived by SLPs as the most frequently used?

4) Do mean differences in the perceived ability levels of using AT exist between SLPs demographic categories (gender, level of education, training, place of work, and years of experience)?

\section{Methodology}

\subsection{Research Design}

This study utilized a quantitative descriptive survey research design to determine SLPs perceptions of the importance and ability to use AT.

\subsection{Participants}

The study sample consisted of SLPs who were working in private and government settings in the cities of Riyadh and Jeddah in the Kingdom of Saudi Arabia, including 55 specialists. The participants comprised 30 males and 25 females. Table 1 shows the distribution of the study sample according to the variables of the study: gender, years of experience, level of education, training, and place of work. 
Table 1: Distribution of the Study Sample According to the Variables of the Study $(\mathrm{N}=55)$

\begin{tabular}{llcc}
\hline Variable & & Frequency & Percent \\
\hline Gender & Male & 30 & 54.5 \\
Years of Experience & Female & 25 & 45.5 \\
& Less than 5 Years & 19 & 34.5 \\
& 5-10 Years & 12 & 21.8 \\
Level of Education & More than 10 Years & 24 & 43.6 \\
& Bachelor & 38 & 69.1 \\
Training & Master & 17 & 30.9 \\
& Yes & 27 & 49.1 \\
Place of work & No & 28 & 50.9 \\
& Private & 26 & 47.3 \\
Total & Government & 29 & 52.7 \\
\hline
\end{tabular}

\subsection{Instrument}

A questionnaire and a self-rating scale were used to obtain the required data. The researcher adopted a questionnaire for SLPs graduate students developed by Currie et al. (1996).

The questionnaire was divided into two sections. The first section involved demographic information (gender, years of experience, level of education, training, and place of work) and the second section comprised 30 items that were divided into eight categories: (1) general computer knowledge, (2) knowledge of AT, (3) assessment of needs related to AT, (4) operation of AT, (5) development and implementation of educational or therapeutic plan, (6) software knowledge, and use of software, (7) consultation, and (8) advocacy: Knowledge of resources and funding.

\subsection{Validity}

The questionnaire was translated into Arabic and then presented to six specialists in the Arabic language, translation, special education, and speech and language pathology from King Abdulaziz University and the University of Jordan. The specialists were asked to rate the items based on the appropriate translation of the items, the clarity and integrity of the meaning and wording, the similarity of items within a category, and any other aspects of the questionnaire items they wished to address. The researcher considered the opinions of the specialists and accordingly amended the wording in several of the items to enable the SLPs to understand the questionnaire easily.

\subsection{Reliability}

The final version of the questionnaire was administered to the exploratory sample of 30 SLPs located in Jeddah. Cronbach's alpha was used to calculate the reliability of the results for the total sample related to importance, which was 0.98 , and ability to use AT, which was also 0.98 .

\subsection{Data Collection Procedure}

The data collection process involved explaining the purpose of the study to the participants, and then asking them to fill out the demographic questionnaire. After completing the questionnaire, the SLPs responded to 30 questions. First, the participants rated the importance of each competency statement using a Likert scale $(4=$ very important; $3=$ moderately important; $2=$ somewhat important; $1=$ not important). Second, the participants rated their ability to apply each competency ( 4 = highly able; 3 = moderately able; 2 = somewhat able; 1 = minimally able).

\subsection{Data Analysis Procedures}

The descriptive statistical principles of means and standard deviations were used to determine the SLPs perceptions of the importance and ability to use AT, and the T-test was used to determine if any statistically significant differences existed among the mean values of the participant responses for each variable. One-way analysis of variance (ANOVA) and post hoc analysis (Scheffe) tests were also used to determine if any statistically significant differences existed among the mean values of the participant responses and the "years of experience" variable.

For purposes of determining the levels, the following criteria was adopted: the means between one and two represent low degree of importance and use level, the means between two and three represent moderate degree of importance and use level, and the means between three and four represent high degree of importance and use level. 


\section{Results}

In this section, the results are organized by research questions.

1) Which competencies of AT were perceived by SLPs as the most important?

To answer this question, the mean scores and standard deviations, rank and level of importance for each category and statement of AT competences were extracted (See table 2).

Table 2: Means, Standard Deviations, Rank, and Level of Importance for Each Category and Statement of AT Competences

\begin{tabular}{|c|c|c|c|c|c|}
\hline Competency ( category and statement) & $\mathrm{M}$ & SD & $\begin{array}{c}\text { Item } \\
\text { NO }\end{array}$ & Rank & $\begin{array}{c}\text { level of } \\
\text { importance }\end{array}$ \\
\hline 1.General Computer Knowledge & 3.68 & .411 & 1 & 1 & High \\
\hline $\begin{array}{l}\text { Knowledge of component parts/functions of computer } \\
\text { hardware and software. }\end{array}$ & 3.76 & .508 & 1 & 1 & High \\
\hline $\begin{array}{l}\text { Execute basis computer operations ( i.e,. using the operating } \\
\text { system,) }\end{array}$ & 3.69 & .505 & 2 & 2 & High \\
\hline Ability to use peripheral devices, such as printers, modems. & 3.58 & .505 & 3 & 3 & High \\
\hline 2.Knowledge of available assistive technology & 3.11 & .796 & 2 & 4 & High \\
\hline Knowledge of available assistive technology devices. & 3.31 & .814 & 4 & 7 & High \\
\hline $\begin{array}{l}\text { Ability to use evaluation criteria for selection/purchase of } \\
\text { assistive technology. }\end{array}$ & 3.04 & .860 & 5 & 16 & High \\
\hline $\begin{array}{l}\text { Knowledge of hardware and software adaptations specific to } \\
\text { an individual's needs. }\end{array}$ & 2.98 & .913 & 6 & 19 & Moderate \\
\hline 3.Assessment of needs related to assistive technology & 3.21 & .768 & 3 & 3 & High \\
\hline $\begin{array}{l}\text { Knowledge of characteristics of individuals for identification } \\
\text { of appropriate candidates for assistive technology. }\end{array}$ & 3.38 & .805 & 7 & 4 & High \\
\hline $\begin{array}{l}\text { Knowledge of factors involved in determining the adequacy } \\
\text { of seating, positioning, and mobility for assistive technology. }\end{array}$ & 3.15 & .848 & 8 & 13 & High \\
\hline $\begin{array}{l}\text { Ability to determine the most appropriate match between the } \\
\text { user and component of the assistive technology system. }\end{array}$ & 3.09 & .928 & 9 & 15 & High \\
\hline 4.Operation of assistive technology & 3.08 & .814 & 4 & 5 & High \\
\hline $\begin{array}{l}\text { Ability to connect and use alternate keyboards and other } \\
\text { adaptive input and output devices. }\end{array}$ & 3.04 & .902 & 10 & 16 & High \\
\hline $\begin{array}{l}\text { Ability to construct low-tech adaptive devices ( i.e., switches, } \\
\text { communication boards) }\end{array}$ & 2.95 & .911 & 11 & 21 & Moderate \\
\hline $\begin{array}{l}\text { Ability to use scanning devices and programs to facilitate } \\
\text { single key and switch operation of computers. }\end{array}$ & 3.11 & .936 & 12 & 14 & High \\
\hline $\begin{array}{l}\text { Ability to use dedicated augmentative communication } \\
\text { devices. }\end{array}$ & 3.24 & .860 & 13 & 11 & High \\
\hline $\begin{array}{l}\text { 5.Development and Implementation of educational/ } \\
\text { therapeutic plan }\end{array}$ & 3.04 & .765 & 5 & 6 & High \\
\hline $\begin{array}{l}\text { Ability to integrate assistive technology into the curriculum to } \\
\text { meet individual needs of students. }\end{array}$ & 3.27 & .757 & 14 & 10 & High \\
\hline $\begin{array}{l}\text { Ability to develop IEP goals and objectives to assistive } \\
\text { technology. }\end{array}$ & 3.31 & .791 & 15 & 7 & High \\
\hline $\begin{array}{l}\text { Ability to evaluate the effectiveness of assistive technology } \\
\text { goals/objective. }\end{array}$ & 3.02 & .892 & 16 & 18 & High \\
\hline $\begin{array}{l}\text { Ability to arrange the physical environment to facilitate the use } \\
\text { of technology in the classroom. }\end{array}$ & 2.87 & .924 & 17 & 23 & Moderate \\
\hline Ability to teach individuals to use input and output devices. & 2.73 & .952 & 18 & 24 & Moderate \\
\hline
\end{tabular}




\begin{tabular}{|c|c|c|c|c|c|}
\hline 6.Software Knowledge and Use of Software & 2.88 & 908 & 6 & 7 & Moderate \\
\hline $\begin{array}{l}\text { Ability to use evaluation criteria to select/purchase } \\
\text { microcomputer software. }\end{array}$ & 2.71 & 1.048 & 19 & 26 & Moderate \\
\hline $\begin{array}{l}\text { Knowledge of software options that allows for modification } \\
\text { of a program. }\end{array}$ & 2.73 & .990 & 20 & 24 & Moderate \\
\hline $\begin{array}{l}\text { Ability to use various types of instructional software } \\
\text { appropriately (e.g., drill/practice, tutorial, simulation, } \\
\text { problem-solving programs). }\end{array}$ & 2.89 & 1.012 & 21 & 22 & Moderate \\
\hline $\begin{array}{l}\text { Ability to use shell programs and authoring systems to } \\
\text { develop computer-assisted lessons. }\end{array}$ & 3.20 & .869 & 22 & 12 & High \\
\hline 7.Consultation & 3.24 & .748 & 7 & 2 & High \\
\hline $\begin{array}{l}\text { Ability to provide consultation and technical assistance to } \\
\text { colleagues. }\end{array}$ & 3.33 & .862 & 23 & 6 & High \\
\hline $\begin{array}{l}\text { Ability to serve as a resource to parents of exceptional children } \\
\text { with regard to their needs in the area of assistive technology. }\end{array}$ & 3.38 & .782 & 24 & 4 & High \\
\hline Ability to use collaboration strategies. & 3.29 & .832 & 25 & 9 & High \\
\hline $\begin{array}{l}\text { Ability to conduct workshops and training programs in the area } \\
\text { of assistive technology. }\end{array}$ & 2.96 & 942 & 26 & 20 & Moderate \\
\hline 8. Advocacy: Knowledge of Resources and Funding & 2.45 & .895 & 8 & 8 & Moderate \\
\hline Sources & & & & & \\
\hline $\begin{array}{l}\text { Ability to locate resources that provide support for the use of } \\
\text { technology in special education at the local/state national level. }\end{array}$ & 2.55 & .899 & 27 & 27 & Moderate \\
\hline $\begin{array}{l}\text { Knowledge of public/private funding sources for technology } \\
\text { for the disabled. }\end{array}$ & 2.44 & .958 & 28 & 29 & Moderate \\
\hline $\begin{array}{l}\text { Ability to obtain third-party payments to secure funding for } \\
\text { assistive technology. }\end{array}$ & 2.29 & .994 & 29 & 30 & Moderate \\
\hline $\begin{array}{l}\text { Develop a resource file for technology in special education } \\
\text { reference and/or dissemination. }\end{array}$ & 2.55 & 1.015 & 30 & 27 & Moderate \\
\hline Overall Categories & 3.06 & .677 & & & High \\
\hline Overall Statements & 3.06 & .677 & & & High \\
\hline
\end{tabular}

As shown in Table 2, the results indicated that the average mean scores of the competency categories ranged between 2.45 and 3.68 on a 4-point scale ranging from 4 "very important" to 1 "not important". The category "General Computer Knowledge" was considered the most important category $(\mathrm{M}=3.68)$ with a high degree of importance level; whereas the category "Advocacy: Knowledge of Resources and Funding Sources” was considered as the least important category $(M=2.45)$ with a moderate degree of importance level. Six of the eight categories had a mean rating of 3.0 or above. The average mean scores for all of the categories were 3.06 with a high degree of importance level.

In addition, the results indicated that the average mean of the competency statements ranged between 2.29 and 3.76. The statement "Knowledge of component parts/functions of computer hardware and software" was considered a highly important statement $(M=3.76)$ with a high degree of importance level; whereas the statement "Ability to obtain third-party payments to secure funding for AT" was considered as the least important statement $(\mathrm{M}=2.29)$ with a moderate degree of importance level. The average mean scores for all of the competency statements were 3.06 with a high degree of importance level.

2) Do mean differences in the perceived level of importance of AT exist between SLPs demographic categories (gender, level of education, training, place of work, and years of experience)?

To answer this question, the mean scores and standard deviations for each category and competency statement were calculated to examine the effect of gender, level of education, training, place of work, and years of experience differences on the perceived importance of AT. To investigate the significant statistical differences among the mean scores, the T- test was used to analyze the variables of gender, level of education, training, and place of work, and ANOVA was used to analyze the variable of years of experience (See tables 3, 4). 
Table 3: Means, Std., and Results of T-test for SLPs Perceptions of the Importance of AT depending on (Gender, Education, Training, and Place of Work) Variables

\begin{tabular}{|c|c|c|c|c|c|c|c|c|c|c|c|}
\hline \multirow[t]{2}{*}{ Variable } & \multirow[t]{2}{*}{ Group } & & \multirow{2}{*}{$\begin{array}{l}\text { Category } \\
1 \\
\end{array}$} & \multirow{2}{*}{$\begin{array}{l}\text { Category } \\
2 \\
\end{array}$} & \multirow{2}{*}{$\begin{array}{l}\text { Category } \\
3 \\
\end{array}$} & \multirow{2}{*}{$\begin{array}{l}\text { Category } \\
4\end{array}$} & \multirow{2}{*}{$\begin{array}{l}\text { Category } \\
5 \\
\end{array}$} & \multirow{2}{*}{$\begin{array}{l}\text { Category } \\
6 \\
\end{array}$} & \multirow{2}{*}{$\begin{array}{l}\text { Category } \\
7 \\
\end{array}$} & \multirow{2}{*}{$\begin{array}{l}\text { Category } \\
8 \\
\end{array}$} & \multirow[t]{2}{*}{ Overall } \\
\hline & & & & & & & & & & & \\
\hline \multirow[t]{6}{*}{ Gender } & Male & Mean & 3.72 & 3.03 & 3.21 & 3.06 & 3.00 & 2.87 & 3.23 & 2.42 & 3.04 \\
\hline & $(\mathrm{N}=30)$ & Std. & .402 & .855 & .771 & .848 & .793 & .953 & .785 & .854 & .700 \\
\hline & Female & Mean & 3.63 & 3.20 & 3.20 & 3.11 & 3.09 & 2.90 & 3.25 & 2.50 & 3.09 \\
\hline & $(\mathrm{N}=25)$ & Std. & .423 & .726 & .782 & .788 & .744 & .869 & .718 & .957 & .662 \\
\hline & & $\mathrm{T}$ & .857 & -.770 & .053 & -.232 & -.421 & -.134 & -.081 & -.341 & -.245 \\
\hline & & Sig. & .395 & .445 & .958 & .817 & .675 & .894 & .935 & .734 & .807 \\
\hline \multirow[t]{6}{*}{ Education } & Bachelor & Mean & 3.62 & 2.98 & 3.12 & 3.07 & 3.01 & 2.85 & 3.16 & 2.39 & 3.01 \\
\hline & $(\mathrm{N}=38)$ & Std. & .419 & .805 & .799 & .814 & .777 & .877 & .761 & .913 & .678 \\
\hline & Master & Mean & 3.80 & 3.39 & 3.39 & 3.10 & 3.11 & 2.96 & 3.41 & 2.59 & 3.18 \\
\hline & $(\mathrm{N}=17)$ & Std. & .374 & .719 & .679 & .839 & .759 & .997 & .712 & .866 & .679 \\
\hline & & $\mathrm{T}$ & -1.530 & -1.800 & -1.206 & -.128 & -.424 & -.402 & -1.135 & -.738 & -.905 \\
\hline & & Sig. & .132 & .078 & .233 & .899 & .673 & .690 & .261 & .464 & .370 \\
\hline \multirow[t]{6}{*}{ Training } & Yes & Mean & 3.86 & 3.80 & 3.86 & 3.77 & 3.70 & 3.61 & 3.81 & 3.08 & 3.67 \\
\hline & $(\mathrm{N}=27)$ & Std. & .296 & .349 & .310 & .465 & .335 & .573 & .429 & .744 & .342 \\
\hline & No & Mean & 3.50 & 2.44 & 2.57 & 2.42 & 2.40 & 2.18 & 2.70 & 1.85 & 2.47 \\
\hline & $(\mathrm{N}=28)$ & Std. & .430 & .454 & .487 & .436 & .446 & .535 & .563 & .542 & .259 \\
\hline & & $\mathrm{T}$ & 3.643 & 12.437 & 11.686 & 11.105 & 12.236 & 9.585 & 8.197 & 7.061 & 14.726 \\
\hline & & Sig. & .001 & .000 & .000 & .000 & .000 & .000 & .000 & .000 & .000 \\
\hline \multirow{6}{*}{$\begin{array}{l}\text { Place of } \\
\text { Work }\end{array}$} & Private & Mean & 3.72 & 3.54 & 3.63 & 3.50 & 3.42 & 3.27 & 3.60 & 2.81 & 3.41 \\
\hline & $(\mathrm{N}=26)$ & Std. & .408 & .574 & .519 & .652 & .551 & .784 & .588 & .813 & .516 \\
\hline & Government & Mean & 3.64 & 2.72 & 2.83 & 2.71 & 2.70 & 2.53 & 2.92 & 2.14 & 2.74 \\
\hline & $(\mathrm{N}=29)$ & Std. & .417 & .777 & .764 & .768 & .781 & .881 & .741 & .857 & .652 \\
\hline & & $\mathrm{T}$ & .666 & 4.378 & 4.490 & 4.104 & 3.863 & 3.252 & 3.705 & 2.964 & 4.193 \\
\hline & & Sig. & .508 & .000 & .000 & .000 & .000 & .002 & .001 & .005 & .000 \\
\hline
\end{tabular}

As shown in Table 3, the mean scores differ based on the gender (male and female) of the respondent. The male group ( $\mathrm{n}=30$ ) had a mean of $\mathrm{M}=3.04$ and a standard deviation of $\mathrm{SD}=.700$; the female group $(\mathrm{n}=25)$ had a mean of $\mathrm{M}=3.09$ and a standard deviation of $\mathrm{SD}=.662$. A T- test between the means yielded $\mathrm{t}(53)=-.245 \mathrm{at} \mathrm{p}=.807$, for $\mathrm{p}$ $=0.05$. Thus, no significant differences were found in the means among the gender groups. For the second variable, differences in the mean scores were found based on the level of education (Bachelor or Master), as shown in Table 3, The SLPs who had a Bachelor degree $(n=38)$ had a mean score of $M=3.01$ and a standard deviation of $\mathrm{SD}=.678$; whereas, the SLPs who had Master degree $(n=17)$ had a mean score of $M=3.18$ and a standard deviation of SD $=.679$. A T-test between the means yielded $\mathrm{t}(53)=-.905$ at $\mathrm{p}=.370$, for $\mathrm{p}=0.05$. These results indicate no significant differences were found between the means of the different education level groups.

Regarding the third variable, as shown in Table 3, differences in the mean scores were found based on the training variable. SLPs who had a previous training on AT $(n=27)$ had a mean score of $M=3.67$ and a standard deviation of $\mathrm{SD}=.342$; whereas SLPs who had no previous training on AT $(n=28)$ had a mean score of $\mathrm{M}=2.47$ and a standard deviation of $\mathrm{SD}=.259$. A T-test between the means yielded $\mathrm{t}(53)=14.726$ at $\mathrm{p}=0.000$, for $\mathrm{p}=0.05$. These results indicate a statistically significant difference between the means of the SLPs who had a previous training on AT and the SLPs who had no previous training on AT. And that the SLPs who had a previous training on AT had a higher level of perceptions of the importance of AT than those who had no previous training on AT.

As for the fourth variable, as shown in Table 3, differences in the mean scores were found based on the place of work. SLPs who worked in private settings $(n=26)$ had a mean score of $M=3.41$ and a standard deviation of SD $=.516$; whereas the SLPs who worked in government settings had a mean score of $\mathrm{M}=2.74$ and a standard deviation of $\mathrm{SD}=.652$. A T-test between the means yielded $\mathrm{t}(53)=4.193$ at $\mathrm{p}=0.000$, for $\mathrm{p}=0.05$. These results indicate a statistically significant difference between the means of SLPs who worked in private settings and SLPs who worked in government settings. The SLPs who worked in private settings produced the most favorable results. Except for the category "General Computer Knowledge", SLPs who worked in private settings had a mean score of M= 3.72 and a 
standard deviation of SD $=.408$; whereas, the SLPs who worked in government settings had a mean score of $\mathrm{M}=$ 3.64 and a standard deviation of $\mathrm{SD}=.417$. A T-test between the means yielded $\mathrm{t}(53)=.666$ at $\mathrm{p}=.508$, for $\mathrm{p}=0.05$. These results indicate no statistically significant difference between the means of SLPs who worked in private settings and SLPs who worked in government settings.

For the purpose of investigating the potential differences in SLPs perceptions of the importance of AT with respect to SLPs Experience variable, as shown in Table 4, differences in the mean scores were found. SLPs with $(<5)$ years of experience $(n=19)$ had a mean score of $M=2.45$ and a standard deviation of SD = .259; and SLPs with (5 -10) years of experience $(\mathrm{n}=12)$ had a mean score of $\mathrm{M}=2.72$ and a standard deviation of SD = .559; and SLPs with (> 10) years of experience $(n=24)$ had a mean score of $M=3.27$ and a standard deviation of $S D=.231$. An ANOVA test between the means yielded $(\mathrm{F}=83.644)$ at $\mathrm{p}=0.000$, for $\mathrm{p}=0.05$. These results indicate a statistically significant difference between the means of different SLPs Experience level groups.

Table 4: Means, Std., and Results of Analysis of Variance (ANOVA) for the SLPs Perceptions of the Importance of AT depending on Experience Variable

\begin{tabular}{ccccccccc}
\hline Category & \multicolumn{2}{c}{$<5$} & \multicolumn{2}{c}{$5-10$} & \multicolumn{2}{c}{$>10$} & S & Sig. \\
& Mean & Std. & Mean & Std. & Mean & Std. & & \\
\hline Category 1 & 3.47 & .435 & 3.50 & .461 & 3.93 & .170 & 10.988 & .000 \\
Category 2 & 2.40 & .424 & 2.86 & .643 & 3.79 & .469 & 43.238 & .000 \\
Category 3 & 2.56 & .545 & 2.86 & .627 & 3.89 & .272 & 46.898 & .000 \\
Category 4 & 2.34 & .384 & 2.81 & .658 & 3.80 & .448 & 51.220 & .000 \\
Category 5 & 2.35 & .394 & 2.75 & .704 & 3.73 & .275 & 56.485 & .000 \\
Category 6 & 2.17 & .559 & 2.40 & .829 & 3.69 & .378 & 44.220 & .000 \\
Category 7 & 2.72 & .513 & 2.77 & .772 & .3 .89 & .233 & 36.702 & .000 \\
Category 8 & 1.86 & .579 & 2.06 & .755 & 3.12 & .707 & 21.250 & .000 \\
Overall & 2.45 & .259 & 2.72 & .559 & 3.72 & .231 & 83.644 & .000 \\
\hline
\end{tabular}

To demonstrate the significant differences between different SLPs Experience level groups, A Scheffe' post hoc test was conducted as shown in Table 5. Results indicated that SLPs with (>10) years of experience had higher level of perceptions about importance of AT competencies in comparison with SLPs with $(<5)$ years of experience (mean difference $=1.27\left(^{*}\right)$ at $\mathrm{p}=0.000$ ), and SLPs with $(5-10)$ had higher level of perceptions about importance of AT competencies in comparison with SLPs with $(<5)$ (mean difference $=.27$ at $\mathrm{p}=.100)$.

Table 5: Post Hoc Analysis (Scheffe's test) for the SLPs Perceptions of the Importance of AT Depending on Experience Variable

\begin{tabular}{|c|c|c|c|c|c|}
\hline Category & Experience & & Mean Difference & Std. Error & Sig \\
\hline \multirow[t]{6}{*}{ Category 1} & $<5$ & $5-10$ & -.03 & 129 & .980 \\
\hline & & $>10$ & $-.46(*)$ & 108 & .000 \\
\hline & $5-10$ & $<5$ & .03 & 129 & .980 \\
\hline & & $>10$ & $-.43(*)$ & 124 & .004 \\
\hline & $>10$ & $<5$ & $.46(*)$ & 108 & .000 \\
\hline & & $5-10$ & $.43(*)$ & 124 & .004 \\
\hline \multirow[t]{6}{*}{ Category 2} & $<5$ & $5-10$ & -.46 & 183 & .053 \\
\hline & & $>10$ & $-1.39(*)$ & 153 & .000 \\
\hline & $5-10$ & $<5$ & .46 & 183 & .053 \\
\hline & & $>10$ & $-.93(*)$ & .176 & .000 \\
\hline & $>10$ & $<5$ & $1.39(*)$ & .153 & .000 \\
\hline & & $5-10$ & $\left..933^{*}\right)$ & .176 & .000 \\
\hline \multirow[t]{6}{*}{ Category 3} & $<5$ & $5-10$ & -.30 & 172 & .230 \\
\hline & & $>10$ & $-1.33(*)$ & .144 & .000 \\
\hline & $5-10$ & $<5$ & .30 & .172 & .230 \\
\hline & & $>10$ & $-1.03(*)$ & .165 & .000 \\
\hline & $>10$ & $<5$ & $1.33(*)$ & 144 & .000 \\
\hline & & $5-10$ & $1.03(*)$ & .165 & .000 \\
\hline \multirow[t]{2}{*}{ Category 4} & $<5$ & $5-10$ & $-.47\left(^{*}\right)$ & 177 & .037 \\
\hline & & $>10$ & $-1.46(*)$ & .148 & .000 \\
\hline
\end{tabular}




\begin{tabular}{|c|c|c|c|c|c|}
\hline & $5-10$ & $<5$ & $.47\left(^{*}\right)$ & .177 & .037 \\
\hline & & $>10$ & $-.99(*)$ & .170 & .000 \\
\hline & $>10$ & $<5$ & $1.46(*)$ & .148 & .000 \\
\hline & & $5-10$ & $.99\left(^{*}\right)$ & .170 & .000 \\
\hline \multirow[t]{6}{*}{ Category 5} & $<5$ & $5-10$ & -.40 & .161 & .053 \\
\hline & & $>10$ & $-1.39(*)$ & .134 & .000 \\
\hline & $5-10$ & $<5$ & .40 & .161 & .053 \\
\hline & & $>10$ & $-.98(*)$ & .155 & .000 \\
\hline & $>10$ & $<5$ & $1.39(*)$ & .134 & .000 \\
\hline & & $5-10$ & $.98(*)$ & .155 & .000 \\
\hline \multirow[t]{6}{*}{ Category 6} & $<5$ & $5-10$ & -.22 & .208 & .560 \\
\hline & & $>10$ & $-1.52(*)$ & .173 & .000 \\
\hline & $5-10$ & $<5$ & .22 & .208 & .560 \\
\hline & & $>10$ & $-1.29(*)$ & .199 & .000 \\
\hline & $>10$ & $<5$ & $1.52\left(^{*}\right)$ & .173 & .000 \\
\hline & & $5-10$ & $1.29\left(^{*}\right)$ & .199 & .000 \\
\hline \multirow[t]{6}{*}{ Category 7} & $<5$ & $5-10$ & -.05 & .181 & .967 \\
\hline & & $>10$ & $-1.16(*)$ & .151 & .000 \\
\hline & $5-10$ & $<5$ & .05 & .181 & .967 \\
\hline & & $>10$ & $-1.11(*)$ & .174 & .000 \\
\hline & $>10$ & $<5$ & $1.16\left(^{*}\right)$ & .151 & .000 \\
\hline & & $5-10$ & $1.11\left(^{*}\right)$ & .174 & .000 \\
\hline \multirow[t]{6}{*}{ Category 8} & $<5$ & $5-10$ & -.21 & .249 & .710 \\
\hline & & $>10$ & $-1.27(*)$ & .208 & .000 \\
\hline & $5-10$ & $<5$ & .21 & .249 & .710 \\
\hline & & $>10$ & $-1.06(*)$ & .239 & .000 \\
\hline & $>10$ & $<5$ & $1.27(*)$ & .208 & .000 \\
\hline & & $5-10$ & $1.06(*)$ & .239 & .000 \\
\hline \multicolumn{6}{|l|}{ Overall } \\
\hline & $<5$ & $5-10$ & -.27 & .124 & .100 \\
\hline & & $>10$ & $-1.27(*)$ & .103 & .000 \\
\hline & $5-10$ & $<5$ & .27 & .124 & .100 \\
\hline & & $>10$ & $-1.00(*)$ & .119 & .000 \\
\hline & $>10$ & $<5$ & $1.27(*)$ & .103 & .000 \\
\hline & & $5-10$ & $1.00\left(^{*}\right)$ & .119 & .000 \\
\hline
\end{tabular}

3) Which competencies of AT were perceived by SLPs as the most frequently used?

To answer this question, the mean scores and standard deviations, rank and level of ability to use for each category and statement of AT competences were extracted (See table 6).

Table 6: Means, Standard Deviations, Rank, and Level of Ability to Use for Each Category and Statement of AT Competences

\begin{tabular}{|c|c|c|c|c|c|}
\hline Competency ( category and statement) & M & SD & $\begin{array}{c}\text { Item } \\
\text { No }\end{array}$ & Rank & $\begin{array}{c}\text { Level of } \\
\text { ability }\end{array}$ \\
\hline 1.General Computer Knowledge & 3.51 & .517 & 1 & 1 & High \\
\hline $\begin{array}{l}\text { Knowledge of component parts/functions of computer hardware and } \\
\text { software. }\end{array}$ & 3.64 & .589 & 1 & 1 & High \\
\hline Execute basis computer operations ( i.e,. using the operating system,) & 3.55 & .538 & 2 & 2 & High \\
\hline Ability to use peripheral devices, such as printers, modems. & 3.35 & .673 & 3 & 3 & High \\
\hline 2.Knowledge of available assistive technology & 2.85 & .920 & 2 & 3 & Moderate \\
\hline Knowledge of available assistive technology devices. & 3.05 & .989 & 4 & 5 & High \\
\hline $\begin{array}{l}\text { Ability to use evaluation criteria for selection/purchase of assistive } \\
\text { technology. }\end{array}$ & 2.76 & .981 & 5 & 17 & Moderate \\
\hline $\begin{array}{l}\text { Knowledge of hardware and software adaptations specific to an } \\
\text { individual's needs. }\end{array}$ & 2.75 & 1.022 & 6 & 19 & Moderate \\
\hline 3.Assessment of needs related to assistive technology & 2.94 & .844 & 3 & 2 & Moderate \\
\hline
\end{tabular}


Knowledge of characteristics of individuals for identification of appropriate candidates for assistive technology.

Knowledge of factors involved in determining the adequacy of seating, positioning, and mobility for assistive technology.

Ability to determine the most appropriate match between the user and component of the assistive technology system.

4.Operation of assistive technology

Ability to connect and use alternate keyboards and other adaptive input and output devices.

Ability to construct low-tech adaptive devices ( i.e., switches, communication boards)

Ability to use scanning devices and programs to facilitate single key and switch operation of computers.

Ability to use dedicated augmentative communication devices.

5.Development and Implementation of educational/ therapeutic plan

Ability to integrate assistive technology into the curriculum to meet individual needs of students.

Ability to develop IEP goals and objectives to assistive technology.

Ability to evaluate the effectiveness of assistive technology

goals/objective.

Ability to arrange the physical environment to facilitate the use of technology in the classroom.

Ability to teach individuals to use input and output devices.

6.Software Knowledge and Use of Software

Ability to use evaluation criteria to select/purchase microcomputer software.

Knowledge of software options that allows for modification of a program.

Ability to use various types of instructional software appropriately (e.g., drill/practice, tutorial, simulation, problem-solving programs).

Ability to use shell programs and authoring systems to develop computer-assisted lessons

\section{Consultation}

Ability to provide consultation and technical assistance to colleagues.

Ability to serve as a resource to parents of exceptional children with regard to their needs in the area of assistive technology.

Ability to use collaboration strategies.

Ability to conduct workshops and training programs in the area of assistive technology.

8. Advocacy: Knowledge of Resources and Funding Sources

Ability to locate resources that provide support for the use of technology in special education at the local/state national level. Knowledge of public/private funding sources for technology for the disabled.

Ability to obtain third-party payments to secure funding for assistive technology.

Develop a resource file for technology in special education reference and/or dissemination.

Overall Categories

Overall Statements

\begin{tabular}{|c|c|c|c|c|}
\hline 3.09 & .948 & 7 & 4 & High \\
\hline 2.85 & .870 & 8 & 9 & Moderate \\
\hline 2.87 & .924 & 9 & 7 & Moderate \\
\hline 2.79 & .948 & 4 & 4 & Moderate \\
\hline 2.75 & .927 & 10 & 19 & Moderate \\
\hline 2.78 & .994 & 11 & 15 & Moderate \\
\hline 2.82 & 1.038 & 12 & 13 & Moderate \\
\hline 2.80 & 1.043 & 13 & 14 & Moderate \\
\hline 2.76 & .931 & 5 & 6 & Moderate \\
\hline 2.85 & 1.008 & 14 & 9 & Moderate \\
\hline 2.89 & 1.031 & 15 & 6 & Moderate \\
\hline 2.78 & .956 & 16 & 15 & Moderate \\
\hline 2.69 & .979 & 17 & 21 & Moderate \\
\hline 2.60 & .955 & 18 & 23 & Moderate \\
\hline 2.59 & .969 & 6 & 7 & Moderate \\
\hline 2.49 & 1.016 & 19 & 25 & Moderate \\
\hline 2.49 & .998 & 20 & 25 & Moderate \\
\hline 2.62 & 1.027 & 21 & 22 & Moderate \\
\hline 2.76 & .981 & 22 & 17 & Moderate \\
\hline 2.77 & .890 & 7 & 5 & Moderate \\
\hline 2.87 & .870 & 23 & 7 & Moderate \\
\hline 2.85 & .951 & 24 & 9 & Moderate \\
\hline 2.84 & .958 & 25 & 12 & Moderate \\
\hline 2.51 & .998 & 26 & 24 & Moderate \\
\hline 1.83 & .840 & 8 & 8 & Low \\
\hline 1.95 & .884 & 27 & 27 & Low \\
\hline 1.82 & .884 & 28 & 28 & Low \\
\hline 1.76 & .860 & 29 & 30 & Low \\
\hline 1.80 & .890 & 30 & 29 & Low \\
\hline 2.72 & .784 & & & Moderate \\
\hline 2.72 & .784 & & & Moderate \\
\hline
\end{tabular}

As shown in Table 6, the results indicated that the average mean scores of the competency categories ranged between 1.83 and 3.51. The category "General Computer Knowledge” was considered the most used category ( $\mathrm{M}=3.51)$, with a high degree of use level; whereas the category "Advocacy: Knowledge of Resources and Funding Sources" was considered as the least used category $(M=1.83)$ with a low degree of use level. One of the eight categories 
produced a mean rating above 3.0. The average mean scores for all of the categories were 2.72 with a moderate degree of use level.

In addition, the results indicated that the average mean scores of the competency statements ranged between 1.76 and 3.64. The statement "Knowledge of component parts/functions of computer hardware and software" was considered the most used statement $(\mathrm{M}=3.64)$ with a high degree of use level; whereas the statement "Ability to obtain third-party payments to secure funding for AT" was considered as the least used statement $(\mathrm{M}=1.76)$ with a low degree of use level. The average mean scores for the entire competency statements were 2.72with a moderate degree of use level.

4) Do mean differences in the perceived ability levels of using AT exist between SLPs demographic categories (gender, level of education, training, place of work, and years of experience)?

To answer this question, the mean scores and standard deviations for each category and competency statement were calculated to determine the effect of gender, level of education, training, place of work, and years of experience differences on the perceived ability to apply AT competencies. To determine the significant statistical differences between the mean scores, the T-test was used to analyze the variables of gender, level of education, training, place of work, and ANOVA was used to analyze the variable of years of experience (See table 7).

Table 7: Means, Std., and Results of T-test for SLPs Perceptions of Ability to Use AT Depending on (Gender, Education, Training, and Place of Work) variables

\begin{tabular}{|c|c|c|c|c|c|c|c|c|c|c|c|}
\hline Variable & Group & & $\begin{array}{l}\text { Category } \\
1\end{array}$ & $\begin{array}{l}\text { Category } \\
2\end{array}$ & $\begin{array}{l}\text { Category } \\
3\end{array}$ & $\begin{array}{l}\text { Category } \\
4\end{array}$ & $\begin{array}{l}\text { Category } \\
5\end{array}$ & $\begin{array}{l}\text { Category } \\
6\end{array}$ & $\begin{array}{l}\text { Category } \\
7\end{array}$ & $\begin{array}{l}\text { Category } \\
8\end{array}$ & Overall \\
\hline \multirow[t]{6}{*}{ Gender } & Male & Mean & 3.58 & 2.83 & 2.91 & 2.76 & 2.71 & 2.58 & 2.73 & 1.87 & 2.71 \\
\hline & $(\mathrm{N}=30)$ & Std. & .471 & .942 & .888 & .966 & .885 & .893 & .910 & .919 & .796 \\
\hline & Female & Mean & 3.43 & 2.88 & 2.97 & 2.82 & 2.82 & 2.61 & 2.81 & 1.79 & 2.74 \\
\hline & $(\mathrm{N}=25)$ & Std. & .565 & .912 & .805 & .945 & .999 & 1.071 & .882 & .752 & .784 \\
\hline & & $\mathrm{T}$ & 1.082 & -.186 & -.270 & -.238 & -.436 & -.132 & -.316 & .334 & -.127 \\
\hline & & Sig. & .284 & .853 & .788 & .813 & .665 & .895 & .754 & .740 & .900 \\
\hline Educatio & Bachelor & Mean & 3.52 & 2.76 & 2.89 & 2.75 & 2.75 & 2.54 & 2.75 & 1.72 & 2.68 \\
\hline \multirow[t]{5}{*}{$\mathrm{n}$} & $(\mathrm{N}=38)$ & Std. & .469 & .890 & .846 & .937 & .893 & .936 & .913 & .836 & .762 \\
\hline & Master & Mean & 3.49 & 3.06 & 3.06 & 2.87 & 2.80 & 2.71 & 2.81 & 2.07 & 2.82 \\
\hline & $(\mathrm{N}=17)$ & Std. & .625 & .981 & .852 & .997 & 1.039 & 1.058 & .859 & .823 & .844 \\
\hline & & $\mathrm{T}$ & .180 & -1.103 & -.699 & -.422 & -.192 & -.585 & -.225 & -1.441 & -.632 \\
\hline & & Sig. & .858 & .275 & .488 & .675 & .848 & .561 & .823 & .155 & .530 \\
\hline \multirow[t]{6}{*}{ Training } & Yes & Mean & 3.75 & 3.57 & 3.67 & 3.61 & 3.56 & 3.37 & 3.51 & 2.46 & 3.42 \\
\hline & $(\mathrm{N}=27)$ & Std. & .420 & .488 & .413 & .429 & .447 & .606 & .493 & .653 & .387 \\
\hline & No & Mean & 3.27 & 2.17 & 2.24 & 1.99 & 1.99 & 1.84 & 2.05 & 1.22 & 2.05 \\
\hline & $(\mathrm{N}=28)$ & Std. & .497 & .682 & .470 & .534 & .535 & .574 & .520 & .468 & .354 \\
\hline & & $\mathrm{T}$ & 3.856 & 8.737 & 11.949 & 12.379 & 11.789 & 9.621 & 10.652 & 8.114 & 13.727 \\
\hline & & Sig. & .0000 & .000 & .000 & .000 & .000 & .000 & .000 & .000 & .000 \\
\hline \multirow{6}{*}{$\begin{array}{l}\text { Place of } \\
\text { Work }\end{array}$} & Private & Mean & 3.60 & 3.29 & 3.38 & 3.34 & 3.24 & 3.01 & 3.20 & 2.27 & 3.14 \\
\hline & $(\mathrm{N}=26)$ & Std. & .550 & .628 & .637 & .616 & .672 & .757 & .696 & .824 & .592 \\
\hline & Government & Mean & 3.43 & 2.46 & 2.54 & 2.29 & 2.34 & 2.22 & 2.38 & 1.44 & 2.34 \\
\hline & $(\mathrm{N}=29)$ & Std. & .479 & .969 & .814 & .928 & .934 & .995 & .873 & .647 & .746 \\
\hline & & $\mathrm{T}$ & 1.278 & 3.743 & 4.249 & 4.850 & 4.063 & 3.302 & 3.834 & 4.174 & 4.375 \\
\hline & & Sig. & .207 & .000 & .000 & .000 & .000 & .002 & .000 & .000 & .000 \\
\hline
\end{tabular}

As shown in Table 7, the mean scores differ based on the gender (male and female) of the respondent. The male group ( $n=30$ ) had a mean of $M=2.71$ and a standard deviation of $S D=.796$; the female group $(n=25)$ had a mean of $\mathrm{M}=2.74$ and a standard deviation of $\mathrm{SD}=.784$. A T- test between the means yielded $\mathrm{t}(53)=-.127 \mathrm{at} \mathrm{p}=.900$, for $\mathrm{p}$ $=0.05$. Thus, no significant differences were found in the means among the gender groups. For the second variable, differences in the mean scores were found based on the level of education (Bachelor or Master), as shown in Table7, The SLPs who had a Bachelor degree $(n=38)$ had a mean score of $M=2.68$ and a standard deviation of SD = .762; whereas the SLPs who had Master degree $(n=17)$ had a mean score of $M=2.82$ and a standard deviation of SD $=.844$. A T-test between the means yielded $\mathrm{t}(53)=-.632$ at $\mathrm{p}=530$, for $\mathrm{p}=0.05$. These results indicate no significant differences were found between the means of the different education level groups.

Regarding the third variable, as shown in Table 7, differences in the mean scores were found based on the training variable. SLPs who had a previous training on AT $(n=27)$ had a mean score of $M=3.42$ and a standard deviation of 
$\mathrm{SD}=.387$; whereas SLPs who had no previous training on AT $(\mathrm{n}=28)$ had a mean score of $\mathrm{M}=2.05$ and a standard deviation of $\mathrm{SD}=.354$. A T-test between the means yielded $\mathrm{t}(53)=13.727$ at $\mathrm{p}=0.000$, for $\mathrm{p}=0.05$. These results indicate a statistically significant difference between the means of the SLPs who had a previous training on AT and the SLPs who had no previous training on AT. And that the SLPs who had a previous training on AT had a higher level of perceptions of ability to use AT than those who had no previous training on AT.

As for the fourth variable, as shown in Table 7, differences in the mean scores were found based on the place of work. SLPs who worked in private settings $(n=26)$ had a mean score of $M=3.14$ and a standard deviation of SD $=.592$; whereas, the SLPs who worked in government settings had a mean score of $\mathrm{M}=2.34$ and a standard deviation of $\mathrm{SD}=.746$. A T-test between the means yielded $\mathrm{t}(53)=4.375$ at $\mathrm{p}=0.000$, for $\mathrm{p}=0.05$. These results indicate a statistically significant difference between the means of SLPs who worked in private settings and SLPs who worked in government settings. The SLPs who worked in private settings produced the most favorable results. Except for the category "General Computer Knowledge", SLPs who worked in private settings had a mean score of M= 3.60 and a standard deviation of $\mathrm{SD}=.550$; whereas the SLPs who worked in government settings had a mean score of $\mathrm{M}=3.43$ and a standard deviation of $\mathrm{SD}=.479$. A T-test between the means yielded $\mathrm{t}(53)=1.278$ at $\mathrm{p}=.207$, for $\mathrm{p}=0.05$. These results indicate no statistically significant difference between the means of SLPs who worked in private settings and SLPs who worked in government settings.

For the purpose of investigating the potential differences in SLPs perceptions of ability to use AT with respect to SLPs Experience variable, as shown in Table 8, differences in the mean scores were found. SLPs with $(<5)$ years of experience $(n=19)$ had a mean score of $M=2.04$ and a standard deviation of SD = .414; and SLPs with (5 -10) years of experience $(n=12)$ had a mean score of $M=2.44$ and a standard deviation of SD = .660; and SLPs with (> 10) years of experience $(n=24)$ had a mean score of $M=3.40$ and a standard deviation of $S D=.438$. An ANOVA test between the means yielded $(\mathrm{F}=44.143)$ at $\mathrm{p}=0.000$, for $\mathrm{p}=0.05$. These results indicate a statistically significant difference between the means of different SLPs Experience level groups.

Table 8: Means, Std., and Results of Analysis of Variance (ANOVA) for the SLPs Perceptions of Ability to Use AT Depending on Experience Variable

\begin{tabular}{ccccccccc}
\hline Category & \multicolumn{2}{c}{$<5$} & \multicolumn{2}{c}{$5-10$} & \multicolumn{2}{c}{$>10$} & F & Sig. \\
& Mean & Std. & Mean & Std. & Mean & Std. & & \\
\hline Category 1 & 3.25 & .543 & 3.42 & .452 & 3.76 & .411 & 6.776 & .002 \\
Category 2 & 2.07 & .644 & 2.83 & .689 & 3.49 & .715 & 22.609 & .000 \\
Category 3 & 2.30 & .496 & 2.64 & .745 & 3.60 & .614 & 26.128 & .000 \\
Category 4 & 1.93 & .526 & 2.58 & .828 & 3.56 & .563 & 37.745 & .000 \\
Category 5 & 1.93 & .626 & 2.55 & .773 & 3.53 & .471 & 39.009 & .000 \\
Category 6 & 1.83 & .662 & 2.21 & .884 & 3.39 & .521 & 31.952 & .000 \\
Category 7 & 2.11 & .614 & 2.35 & .765 & 3.50 & .521 & 31.058 & .000 \\
Category 8 & 1.32 & .545 & 1.29 & .620 & 2,51 & .623 & 27.535 & .000 \\
Overall & 2.04 & .414 & 2.44 & .660 & 3.40 & .438 & 44.143 & .000 \\
\hline
\end{tabular}

To demonstrate the significant differences between different SLPs Experience level groups, A Scheffe' post hoc test was conducted as shown in Table 9. Results indicated that SLPs with $(>10)$ years of experience had higher level of perceptions about ability to use AT competencies in comparison with SLPs with $(<5)$ years of experience (mean difference $=1.36\left(^{*}\right)$ at $\mathrm{p}=0.000$ and SLPs with $(5-10)$ had higher level of perceptions about ability to use AT competencies in comparison with SLPs with $(<5)$ (mean difference $=.40$ at $\mathrm{p}=0.94)$. 
Table 9: Post Hoc Analysis (Scheffe's Test) for the SLPs Perceptions of the Ability to Use AT Depending on Experience Variable

\begin{tabular}{|c|c|c|c|c|c|}
\hline Category & Experience & & Mean Difference & Std. Error & Sig. \\
\hline \multirow[t]{6}{*}{ Category 1} & $<5$ & $5-10$ & -.17 & .173 & .616 \\
\hline & & $>10$ & $-.52\left(^{*}\right)$ & .144 & .003 \\
\hline & $5-10$ & $<5$ & .17 & .173 & .616 \\
\hline & & $>10$ & -.35 & .166 & .122 \\
\hline & $>10$ & $<5$ & $.52(*)$ & .144 & .003 \\
\hline & & $5-10$ & .35 & .166 & .122 \\
\hline \multirow[t]{6}{*}{ Category 2} & $<5$ & $5-10$ & $-.76(*)$ & .253 & .015 \\
\hline & & $>10$ & $-1.42(*)$ & .211 & .000 \\
\hline & $5-10$ & $<5$ & $.76(*)$ & .253 & .015 \\
\hline & & $>10$ & $-.65\left(^{*}\right)$ & .242 & .034 \\
\hline & $>10$ & $<5$ & $1.42(*)$ & .211 & .000 \\
\hline & & $5-10$ & $.65\left(^{*}\right)$ & .242 & .034 \\
\hline \multirow[t]{6}{*}{ Category 3} & $<5$ & $5-10$ & -.34 & .224 & .323 \\
\hline & & $>10$ & $-1.30(*)$ & .187 & .000 \\
\hline & $5-10$ & $<5$ & .34 & .224 & .323 \\
\hline & & $>10$ & $-.96\left(^{*}\right)$ & .215 & .000 \\
\hline & $>10$ & $<5$ & $1.30(*)$ & .187 & .000 \\
\hline & & $5-10$ & $.96\left(^{*}\right)$ & .215 & .000 \\
\hline \multirow[t]{6}{*}{ Category 4} & $<5$ & $5-10$ & $-.65\left(^{*}\right)$ & .228 & .023 \\
\hline & & $>10$ & $-1.63(*)$ & .190 & .000 \\
\hline & $5-10$ & $<5$ & $.65\left(^{*}\right)$ & .228 & .023 \\
\hline & & $>10$ & $-.98\left(^{*}\right)$ & .218 & .000 \\
\hline & $>10$ & $<5$ & $1.63(*)$ & .190 & .000 \\
\hline & & $5-10$ & $.98(*)$ & .218 & .000 \\
\hline \multirow[t]{6}{*}{ Category 5} & $<5$ & $5-10$ & $-.62(*)$ & .221 & .025 \\
\hline & & $>10$ & $-1.61(*)$ & .184 & .000 \\
\hline & $5-10$ & $<5$ & $.62(*)$ & .221 & .025 \\
\hline & & $>10$ & $-.98\left(^{*}\right)$ & .212 & .000 \\
\hline & $>10$ & $<5$ & $1.61(*)$ & .184 & .000 \\
\hline & & $5-10$ & $.98(*)$ & .212 & .000 \\
\hline \multirow[t]{6}{*}{ Category 6} & $<5$ & $5-10$ & -.38 & .244 & .306 \\
\hline & & $>10$ & $-1.56(*)$ & .203 & .000 \\
\hline & $5-10$ & $<5$ & .38 & .244 & .306 \\
\hline & & $>10$ & $-1.18(*)$ & .234 & .000 \\
\hline & $>10$ & $<5$ & $1.56(*)$ & .203 & .000 \\
\hline & & $5-10$ & $1.18(*)$ & .234 & .000 \\
\hline \multirow[t]{3}{*}{ Category 7} & $<5$ & $5-10$ & -.25 & .226 & .548 \\
\hline & & $>10$ & $-1.39(*)$ & .188 & .000 \\
\hline & $5-10$ & $<5$ & .25 & .226 & .548 \\
\hline
\end{tabular}




\begin{tabular}{|c|c|c|c|c|c|}
\hline & & $>10$ & $-1.15\left(^{*}\right)$ & .216 & .000 \\
\hline & $>10$ & $<5$ & $1.39(*)$ & .188 & .000 \\
\hline & & $5-10$ & $1.15\left(^{*}\right)$ & .216 & .000 \\
\hline \multirow[t]{6}{*}{ Category 8} & $<5$ & $5-10$ & .02 & .220 & .994 \\
\hline & & $>10$ & $-1.19\left(^{*}\right)$ & .183 & .000 \\
\hline & $5-10$ & $<5$ & -.02 & .220 & .994 \\
\hline & & $>10$ & $-1.22(*)$ & .211 & .000 \\
\hline & $>10$ & $<5$ & $1.19\left(^{*}\right)$ & .183 & .000 \\
\hline & & $5-10$ & $1.22(*)$ & .211 & .000 \\
\hline \multirow[t]{6}{*}{ Overall } & $<5$ & $5-10$ & -.40 & .179 & .094 \\
\hline & & $>10$ & $-1.36(*)$ & .149 & .000 \\
\hline & $5-10$ & $<5$ & .40 & .179 & .094 \\
\hline & & $>10$ & $-.96(*)$ & .172 & .000 \\
\hline & $>10$ & $<5$ & $1.36\left(^{*}\right)$ & .149 & .000 \\
\hline & & $5-10$ & $.96\left(^{*}\right)$ & .172 & .000 \\
\hline
\end{tabular}

\section{Discussion}

The current study aimed to investigate SLPs perceptions of the importance and ability levels of using AT in the Kingdom of Saudi Arabia, and the relationship of these perceptions with gender, level of education, training, place of work, and years of experience.

The respondents considered all of the item statements "somewhat important" to "very important" for personnel working with individuals who have communication disabilities $(M=2.29-3.76)$. This result indicates an agreement among the SLPs regarding the importance of AT competencies in teaching communication to individuals with communication disorders. This result is consistent with the findings of Currie et al. (1996), which indicated that all of the respondents in the study considered all of the item statements to be either "very important," or "moderately" important, except for one item statement. The results of this study were also consistent with the findings of Khaleel and Al-Dawaideh (2012), in which all of the respondents in the study considered all of the item statements regarding speech and language competences to be either "moderately important" or "very important," and with (Eugene, 2006; Ismail et al., 2010) studies which emphasized the importance of integration of technology in teaching and learning. This result was attributed to the conviction that SLPs must learn to apply AT competences to help individuals with various disabilities communicate with others. However, this result was not consistent with the findings of Balandin and Iacono (1998), in which the SLPs were not advised to use AAC because they possess limited knowledge and skills related to AT. In addition, the respondents rated the competency statements to indicate their ability to apply each competency, and they rated themselves as being "minimally" to "highly" capable $(\mathrm{M}=1.76-3.64)$. Twenty-six of the 30 item statements produced a mean rating above 2.0, except for items 27, 28, 29, and 30 for the "Advocacy: Knowledge of Resources and Funding Sources," category, which produced a mean below $2.0(\mathrm{M}=1.76-1.95)$. This low level of ability contrasts with the respondent ratings of the importance of each item. This result is consistent with the findings of Currie et al. (1996), in which the respondents rated themselves as "minimally" to "somewhat" confident. This result may be attributed to the insufficient education they received in their graduate programs on speech and language pathology. In addition, a majority of the SLPs were uncomfortable with using AT devices, despite believing that AT competencies are important.

The three highest-ranked ability level items were in the category of "General Computer Knowledge" (Items 1, 2, and 3) "Knowledge of AT" (Item 4), and "Assessment of Needs Related to AT" (Item 7), in which the respondents believed they were "moderately" to "highly" capable of applying. This result was attributed to most of the SLPs having personal computers at home. In addition, the SLPs took graduate courses on speech and language pathology and subsequently acquired a general knowledge of AT devices without receiving training and acquired knowledge of the characteristics that can be used to identify appropriate candidates for AT.

The results of this study revealed that no statistically significant differences in perceived importance or ability 
existed between male and female groups in all the categories and the total score of scale $(\mathrm{M}=3.04$ for males, $\mathrm{M}=$ 3.09 for females). This finding is consistent with that of Khaleel and Al-Dawaideh (2012). This result indicates that both male and female SLPs perceive the importance of AT competencies similarly, and they possess similar competences in using technology for teaching communication. Furthermore, they experience difficulty in applying AT competences for the same reasons.

Regarding the experience variable, the results indicated that a statistically significant difference in perceived importance and ability existed between the participants based on teaching experience in all the categories and the total score of scale. This result may be related to fact that the SLPs with more experience and knowledge of AT acquired through seminars, workshops, and other specialists are more capable of using AT and recognizing the importance of AT.

Furthermore, the results revealed that no statistically significant differences in perceived importance and ability existed between the participants based on level of education in all the categories and the total score of scale. This result indicated that AT courses on speech and language taught in universities that allow students a limited amount of credit hours do not provide graduates with the necessary professional competences that can be used in the field. This result is consistent with the finding of Khaleel and Al-Dawaideh (2012) indicated no statistically differences based on level of education. Despite this result, however, these courses still contribute to SLPs perceptions of the importance of these competences in the speech and language field.

Regarding the training variable, the results revealed that statistically significant differences in perceived importance and ability existed among the participants based on training in all the categories and the total score of scale. The SLPs who had received specialized training in AT produced more favorable results than the other SLPs did. This result may be related to that AT information provided to undergraduate students is insufficient in emphasizing the importance of AT competences and being able to apply these competences; whereas SLPs who receive specialized training realize the importance of these competences and apply them in the field. This result is consistent with the finding of Marvin et al. (2003), in which most of the participants possessed a limited knowledge of AT because they had received insufficient information from graduate courses. This result is also consistent with the finding of Balandin and Iacono (1998), who stated that SLPs are not advised to use AAC because they possess limited knowledge and skills related to AAC.

Finally, the current study also revealed that statistically significant differences in perceived importance and ability existed among the participants based on place of work in all the categories and the total score of scale, except for the category "General computer knowledge." SLPs who worked in private places produced more favorable results than those who worked in other settings. This result indicates that using AT to address communication disorders is more suitable in private settings. This result may be attributed to the training SLPs receive regarding various types of AT devices and the necessary tools and equipment provided to them in a private settings. Furthermore, SLPs may be more motivated to develop their competences and skills, compete with others, and maintain employment in private settings than in other employment settings. This result is consistent with the finding of Wehmeyer (1998), which indicated that funding is a barrier that prevents the adoption of AT. The private settings charge fees for providing treatment and diagnosis enable them often provide AT devices. However, this result is not consistent with the finding of Khaleel and Al-Dawaideh (2012), in which no statistically significant differences among SLP competences associated with place of work existed.

Several limitations were observed in current study: the sample size was small and the participants were all from Riyadh and Jeddah in the Kingdom of Saudi Arabia. The overall, however, the results of this study should be treated with caution, as it is limited to SLPs perceptions of importance and ability to use AT rather than actual perceptions.

The researcher recommends that future studies be conducted to examine SLPs knowledge and skills in relation to the importance and ability of using AT in a large region in Kingdom of Saudi Arabia, and to address all types of employment settings (schools, special education centers, private clinics, and hospitals). Furthermore, the researcher recommends that these AT competences be included in the preparation of programs and rehabilitation courses for SLPs in universities. 


\section{Conclusion}

The study aimed at determining SLPs perceptions of the importance and ability of using AT and to establish whether these perceptions vary according to gender, years of experience, level of education, training, and place of work. The results revealed a number of results regarding SLPs perceptions toward the importance and ability of using AT. The findings indicated that all of the SLPs involved in this study considered all of the item statements to be important, and the respondents rated themselves as "minimally" to "highly" capable of using AT. In addition, no statistically significant differences in perceived importance and ability to use existed between gender groups and level of education groups. The results also indicated that a statistically significant difference in perceived importance and ability to use existed among the participants based on teaching experience groups, training groups, and place of work groups.

\section{Acknowledgement}

The researcher acknowledge the administrators of services settings and SLPs' support, guidance, and encouragement in accomplishing this study.

\section{References}

Al- Khateeb, J. (2005). Uses of technology in special education. Amman: Jordan, Wael Publisher.

American Speech - Language - Hearing Association. (2005). Roles and responsibilities of speech-language pathologists with respect to alternative communication: Position statement. Retrieved from http://www.asha.org/NR/ rdonlyres/BA19B90C-1C17-4230-86A8-83B4E12E4365/0/v3PSaac.pdf

American Speech- Language Hearing Association Ad Hoc Committee on Communication Processes and Non Speaking Communication. (1981). American Speech and Hearing Association, 23(8), 577-581.

Balandin, S., \& Iacono, T. (1998). AAC and Australian speech pathologists report on national survey. Augmentative and Alternative Communication, 14, 239-249. http://dx.doi.org/10.1080/07434619812331278416

Beukelman, D. R., \& Mirenda, P. (2005). Augmentative alternative communication. Paul H., Brooks Publishing Co., Inc.

Chmiliar, L. (2007). Perspective on assistive technology: What teachers, health professionals, and speech and language pathologists have to say. Developmental Disabilities Bulletin, 35(1), 1-17. Retrieved from ERIC database (EJ812642)

Compton, M.Y., Tucker, D. A., \& Flynn, P. F. (2009). Preparation and perceptions of speech-language pathologists working with children with cochlear implants. SAGE Publications and Hammill Institute on Disabilities Journal, 30(3), 142-154. http:// dx.doi.org/ 10.1177/1525740/08325554

Currie, S. P, Carr, C. S., \& Torrey, C. C. (1996). Technology training issues: Emerging and expanding roles of speech-language pathologists. National Student Speech Language Hearing Association Journal, 23, 19-27. Retrieved from http://www.asha.org

Eugene, J. (2006). How teachers integrate technology and their beliefs about learning: is there a connection? Journal of Technology and Teacher Education, 14(3), 581-597.

Green, J. (2011). Assistive technology in special education: Resources for education, intervention, and rehabilitation. Prufrock Press Inc.

Individuals with Disabilities Education Act Amendments of 1997, P. L. 105-17(June 4 1997). 20 U.S.C. § 1400 et seq Institute for Matching Person an Technology. Matching person and technology assessment process. Retrieved from http//members.aol.com/imp97/mptdesc.html

Ismail, S., Almekhlafi, A., \& Al-Mekhlafy, M. (2010). Teachers' perceptions of the use of the technology in teaching languages in United Arab Emirates" schools. International Journal for Research in Education, No. 27. Retrieved from http://www.cedu.uaeu.ac.ae/journal/docs/pdf/pdf27/7.pdf

Khaleel, Y., \& Al-Dawaideh, A. (2012). Level of importance and possession of speech and language pathologist's competences according to the standards of the Council for Exceptional Children in the Saudi Arabia kingdom. Education and Childhood Journal, Alexandria University, 9(1), 61-105. 
Marvin, A. L., Montano, J. J., \& Gould, P. E. (2003). Speech-language pathologist's perceptions of their training and experience in using alternative and augmentative communication. Contemporary Issues in Communication Science and Disorders, 30, 76-83. Retrieved from http://www.asha.org

Merill, N., Yilon-Hamivitz, S., Weiss, T., Lebel, T., \& Seligman-Wine, J. (2000). Students with severe communication impairment in special education settings in Israel: A demographic Survey. Augmentative and Alternative Communication: ISAAC-Israel, 16, 38-44.

Reed, R. P. (2007). A resource guide for teachers and administrators about assistive technology. Winconsim Assistive Technology Initiative. Retrieved from http//www.wati.org/content/.../ATResourceGuideDec08.pdf

Reed, R. P., \& Laham, A. E. (2005). A resource guide for teachers and administration about assistive technology. Retrieved from http//www.mcpherson.com/418/special_ed/AssistiveTechnology/WisconsinAssTechGuide.pdf

Wehmeyer, M. L. (1998). National survey of the use of assistive technology by adults with mental retardation. Journal of Mental Retardation, 36(1), 44-51.

Wynne, K. M., \& Hurst, S. D. (1995). Legal issues and computer use by school-based audiologists and speech-language pathologists. American Speech -Language Hearing Association, 26, 251-255. Retrieved from http://www.asha.org 